\section{ASSESSMENT OF PAIN DURING ENDOTRACHEAL SUCTIONING IN PEDIATRIC INTENSIVE CARE UNIT (PICU)}

\author{
D. Sonmez Duzkaya1', S. Kuguoglu²
}

${ }^{1}$ Pediatric Emergency and Intensive Care, Istanbul University, Istanbul Medical Faculty, ${ }^{2}$ Pediatric Nursing, Acibadem University, Health Science Faculty Division of Nursing, Part Time Faculty, Istanbul, Turkey

Background and aims: This research is planned as a two leveled definitive and comparative; one that evaluates pain during the endotracheal aspiration in PICU.Universe of the study is composed of patients and nurses who applied .

Methods: Cases are selected trough PICU patients who filled the study criteria and nurses who give care them in a time interval of 1 January-2 July 2008. Rutine endotracheal aspiration was applied as the first level of study. For the second level inquiry on knowledge of nurses about aspiration is applied to nurses and then they are asked to do aspiration according to guideline of aspiration they were told. Data was obtained with questionnaire. Both FLACC pain and Wong-Baker facial determination pain scales were used to evaluate the patient's pain. All the optained data were evaluated

Results: \%33,8(22) of patients are between 1 month to 1 year old and \%64,2 (42) of them are male. During the endotracheal aspiration, oxygen saturation of $\% 83,1(54)$ patients was decreased, $\% 81,5(54)$ retched ,\%67,7(44) was troubled. Although group 1 patients had higher scores on Wong-Baker pain facial determination scale and FLACC scale no statistical difference was found amount two groups $(p>0,05)$. Patients who had bolus dozes of analgesic and sedative drugs had lower Wong-Baker facial pain determination score $(4,38+$ 0,96 (4)) and FLACC score(4,61+- 1,94(4)) $(p>0,05)$ According to these; patients are troubling because of pain and pain is slightly but related with aspiration.

Conclusions: So aspiration guideline is recommended to be used in PICU during the endotracheal suction.

\section{SAFETY OF CHILDREN IN HOSPITAL}

D. Beštak, K. Šešo

\section{Department of Pediatrics, University Hospital Center Zagreb, Zagreb, Croatia}

Background: Hospitals are places where children should have best care, but sometimes hospitals are places where accidents can occur. Accident awareness among parents and nurses is important in preventing the accidents.

Methods: Questionnaire fulfilled by nurses, parents and nursing students.

Results: Prevention of accidents is one of the most important goals at pediatric wards. Accidents may be prevented and it is important to promote that fact among medical stuff as well as among the parents. Accident report is important for adequate medical help and it's written form is an objective document by which the event can be analyzed and in that way preventing the future accidental event.

Conclusions: Thinking about prevention and applying security measures along with written accident report if accident happens are useful measures in reducing the number of accidents.

\section{3}

\section{ADVERSE DRUG REACTIONS IN CHILDREN ADMITTED TO A TERTIARY CARE CENTER}

\author{
S. Águeda, R. Jorge, J. Rebelo, A. Maia, \\ I. Azevedo, C. Afonso \\ Department of Pediatrics, Hospital de São João, \\ E.P.E., Porto, Portugal
}

Background and aims: Knowledge of adverse drug reactions (ADR) is scant in the pediatric population compared to adults. Our goul was to determine the incidence of ADR in hospitalized patients, identify the drugs involved, the most frequent clinical manifestations and their follow-up.

Methods: Retrospective study of clinical records of patients hospitalized in a tertiary care hospital, in which an ADR was reported, over a 16 years period.

Results: We identified 188 ADR, $0.46 \%$ of total admissions. The ADR was the reason for admission in $20,2 \%$. The most common diagnoses were infectious diseases. Children had a mean age of 
$4.0 \pm 3.8$ years, $57,4 \%$ were male and a past history of allergy or immunodeficiency was reported in $26.7 \%$. The most frequent clinical manifestations were mucocutaneous (51.6\%), followed by cardiovascular (14.4\%) and gastrointestinal $(12.2 \%)$. The drugs most often implicated were antibiotics (40.3\%), especially vancomycin (19.7\%) and amoxicillin-clavulanate $(18.4 \%)$, followed by chemotherapeutic agents $(8.0 \%)$, vaccines $(6.9 \%)$ and steroids (5.9\%). Intravenous administration was associated with $54,3 \%$ of ADR and the time from first drug administration to ADR was > 48 hours in $51.6 \%$. The reactions were mild in $83.5 \%$, but 3 cases required admission to ICU, with one fatality. Only 14 children (7.4\%) were referred to a consultation for follow-up.

Conclusions: Our data showed a low incidence of ADR compared to recent prospective studies, but the type of reactions and drugs involved were similar. It is necessary to alert health professionals to occurrence of ADR in order to implement their coding and reporting to the authorities.

\section{4}

THE ROLE OF PSIDII GUAVA LEAF EXTRACT TO INCREASE PLATELET LEVEL IN DENGUE VIRUS INFECTION

S. Soegijanto ${ }^{1,2,3,4}$, D. Azhali ${ }^{1}$, A.R. Tumbelaka ${ }^{1}$, R. Rufiati ${ }^{1}$, D. Anggraini ${ }^{1}$, M. Rahma Karyati ${ }^{1}$

${ }^{1}$ Child Health, Institute Tropical Disease, ${ }^{2}$ Child Health, Dr. Soetomo General Hospital, ${ }^{3}$ Child Health of Medical Faculty, Airlangga University, Surabaya, ${ }^{4}$ Child Health of Medical Faculty, Indonesia University Jakarta and Padjajaran University, Bandung, Indonesia

Background: The pathogenesis of DHF is still unknown; $A D E \&$ virulency of dengue virus caused plasma leakage thrombocytopenia and haemorrhagic clinical manifestation of DHF cases; resuscitation fluid and increasing thrombocyte to prevent severity of Dengue Haemorrhagic cases.

The aim of study: To find the role of Psiidii guava leaf extract liquid in DHF cases.

Material \& method: The study had been done at Dr. Soetomo hospital Surabaya, Hasan Sadikin hospital Bandung, and Dr. Cipto Mangunkusumo hospital Jakarta, on January 31, 2007 to February 01, 2008; 93 cases DHF were recruiting for study; 54 DHF cases grade $1 \& 2$ as study group. And 39 DHF cases grade $1 \& 2$ as control; study group got resuscitation fluid and Psiidii guava leaf extract liquid. Control group got resuscitation fluid and placebo. All cases were followed everyday until discharge by paediatrician in charge.

Based on increasing thrombocyte number, 54 cases of study showed $86,47 \pm 86,23$ and 93 cases of control group showed $32.807 \pm 67,56$ and based on grade of thrombocyte number 40 cases of study group showed increasing number of thrombocyte, and 7 decrease. 23 control groups were increase and 15 control group were decrease. The result showed significant differences $p<0,010$.

Conclusion: Psiidii guava leaf extract could significantly increase thrombocyte in DHF cases.

Keyword: Dengue virus, ADE, thrombocyt, DHF \& Psiidii guava leaf extract liquid

1255

\section{MATERNAL BETAMETHASON ADMINISTRATION IS AN INDICATOR BUT NOT AN INDEPENDENT RISK FACTOR FOR RAISED 17-HYDROXYPROGESTERONE AT NEONATAL SCREENING}

\section{G. Pauwels ${ }^{1}$, A. Meulemans ${ }^{2}$, K. Allegaert ${ }^{3}$, L. Régal ${ }^{1}$}

${ }^{1}$ Department of Paediatrics, University Hospitals Leuven, Leuven, 'Laboratory of Pediatrics, ULB, Brussels, ${ }^{3}$ Neonatal Intensive Care Unit, University Hospitals Leuven, Leuven, Belgium

Introduction: Prenatal maternal betamethason administration to induce lung maturation might subsequently interfere with neonatal screening of congenital adrenal hyperplasia (CAH). We therefore evaluated the impact of prenatal betamethason and other risk factors on 17-hydroxyprogesterone (17OHP) in filter-paper blood.

Methods: Retrospective collection of clinical characteristics (birth weight, gestational age, small for gestational age, prenatal betamethason, day of sampling, duration respiratory support) in neonates admitted in a single NICU and with an increased 17-OHP (>30umol/L) at initial screening that turned out to be false positive. Data reported by median and range or incidence. Clinical characteristics were compared with individual 17-OHP (correlation, Mann Withney $U$, multiple regression).

Results: In 91 (median 73, range 31-463 umol/L) cases, BW, GA, SGA, prenatal betamethason, day 